\title{
Comparative Study between Setting Position Versus Left Lateral Position Effects During Spinal Anesthesia Block in Caesarean Section
}

Mohamed Mohamed Salah Shamlool ${ }^{1}$, Maamon Mohamed Ismail ${ }^{1}$, Khaled Shehata Ali Elshaer ${ }^{2 *}$

Department of ${ }^{1}$ Anesthesiology and Intensive Care, Faculty of Medicine, Al-Azhar University,

Cairo and ${ }^{2}$ Damanhour Teaching Hospital, Damanhour, Egypt

*Corresponding author: Khaled Shehata Ali Elshaer, Mobile: (+20)01008168750, E-Mail: khaled.elshaer90@gmail.com

\begin{abstract}
Background: A caesarean section is recommended when vaginal delivery is a threat to the mother or child.

Aim of study: The aim of the study was to compare the effect of position (sitting versus left lateral) during spinal anesthesia application in cesarean section. The sample of the study was 60 patients.

Patients and Methods: Half of the patients received spinal analgesia consisting of $2 \mathrm{ml}(10 \mathrm{mg})$ of $0.5 \%$ hyperbaric bupivacaine and $25 \mu \mathrm{g}$ fentanyl in the sitting position, while the other half received spinal analgesia consisting of 2 $\mathrm{ml}(10 \mathrm{mg})$ of $0.5 \%$ hyperbaric bupivacaine and $25 \mu \mathrm{g}$ fentanyl in the left lateral position.

Results: both Left lateral and sitting position in spinal anesthesia in cesarean section have the same effect on hemodynamics, also satisfactory sensory and motor block can be achieved in both positions. So left lateral position is safe and can be performed in parturient who are sedated, in pain or using entonox.

Conclusion: Satisfactory sensory and motor blockade were successfully achieved in both sitting and lateral positions during intrathecal injection in cesarean section without significant difference in the hemodynamic changes or motor blockade. With superiority of faster onset of sensory blockade in lateral position, while sitting position is more comfortable for he parturient.
\end{abstract}

Keywords: Spinal Anesthesia, Sitting, Left Lateral, Cesarean Section.

\section{INTRODUCTION}

A caesarean section is recommended when vaginal delivery is a threat to the mother or child. Not all of these cases are mandatory, and in many cases the obstetrician must use the discretion to determine if a cesarean section is necessary. Some signs of cesarean delivery are: Prolonged labor or failure to progress (obstetrics), fetal distress, umbilical cord prolapse, uterine rupture, placental problems (placenta previa, placental abruption or placenta accreta), abnormal presentation (posterior or transverse positions), failed labor induction, failed instrumental, overly large baby (macrosomia), umbilical cord abnormalities (vasa previa, multi-lobate including bi-lobate and succenturiate-lobed placentas, velamentous insertion) and contracted pelvis ${ }^{(\mathbf{1}, \mathbf{2})}$.

Other complications of pregnancy, preexisting conditions and concomitant disease such as preeclampsia, hypertension, multiple births, precious (High Risk) fetus, HIV infection of the mother, Sexually transmitted infections such as genital herpes (which can be passed on to the baby if the baby is born vaginally, but can usually be treated in with medication and do not require a caesarean section $)^{(2)}$.

Also, if we have problems with the healing of the perineum (from previous childbirth or Crohn's Disease) or lack of obstetric skill (obstetricians not being skilled in performing breech births, multiple births, etc). In most situations' women can birth under these circumstances naturally. However, obstetricians are not always trained in proper procedures ${ }^{(\mathbf{3})}$.

The choice of anesthesia for caesarean delivery is determined by several factors, including the process indicator, urgency, partial desire, and anesthesiologist and surgeon skills ${ }^{(4)}$.

There are many indications for general anesthesia, some of which are failed regional anesthesia, conditions where regional anesthesia is contraindicated, maternal request and life-threatening fetal compromisewhen there might not be adequate time to perform a regional technique. In the past, general anesthesia was considered to be the technique of choice. However, the proportion of caesarean sections performed under general anesthesia has dropped significantly. In the United States, general anesthesia is used for less than 5\% of electivecaesarean deliveries. For emergency deliveries, the rate varies between 15 and $30 \%{ }^{(5,6)}$.

Regional anesthesia is the most popular form of anesthesia for caesarean section due to avoiding risks of general anesthesia, for better postoperative pain relief and also for keeping the woman awake to see her baby just after birth ${ }^{(7)}$. Approximately $95 \%$ of caesarean sections are performed under regional analgesia in United States, nearly evenly split between spinal and epidural analgesia ${ }^{(8)}$. Although this can be achieved by spinal or epidural anesthesia, spinal anesthesia is a simple technique with low failure rate, rapid onset and low drug dose ${ }^{(9)}$.

Hypotension is common after spinal anesthesia $^{(\mathbf{1})}$. It may be due in part to cephalad spread of local anesthetic in the subarachnoid space and also to aortocaval compression by the gravid uterus. These factors are influenced by the parturient position during and immediately after subarachnoid injection. Prophylactic measures to reduce the incidence of 
hypotension include fluid loading, left lateral uterine displacement and the use of vasopressors. Despite these prophylactic measures hypotension has been shown to have an incidence of $30-90 \%(2,3)$.

By influencing the speed of local anesthetic maternal position may affect the speed of onset of sensory block. However, studies of different maternal positions have produced conflicting results with respect to hemodynamic stability and speed of onset of block $^{(4,5)}$.

\section{AIM OF THE WORK}

The aim of the study is to compare the effect of position (sitting versus left lateral) during spinal anesthesia application in cesarean section.

\section{PATIENTS AND METHODS}

After approval of the local Ethics Committee and having an informed written consent from the parturient included in the study, the study was carried out on sixty female patients' full-term pregnancies ASA I scheduled for elective CS under spinal anesthesia in Al-Azhar University hospitals (Bab El-sheareya and El-Hussein), between June 2018 and December 2018.

\section{Group (1):}

The patients were subdivided into 2 groups:

Thirty parturient received spinal analgesia consisting of $2 \mathrm{ml}(10 \mathrm{mg})$ of $0.5 \%$ hyperbaric bupivacaine and $25 \mu \mathrm{g}$ fentanyl in the sitting position.

\section{Group (2):}

30 parturient received spinal analgesia consisting of $2 \mathrm{ml}(10 \mathrm{mg})$ of $0.5 \%$ hyperbaric bupivacaine and $25 \mu \mathrm{g}$ fentanyl in the left lateral position.

\section{- Exclusion criteria:}

1. contraindications to spinal anesthesia:

- Absolute contraindications to spinal anesthesia:

- Patient refusal.

- Sepsis at the site of injection.

- Hypovolemia.

- Coagulopathy.

- Increased intracranial pressure.

* Relative contraindications:

- Infection distinct from the site of injection.

2. Parturient ASA more than I.

3. Polyhydraminos, oligohydraminos or multiple pregnancy.

4. Parturient less than $150 \mathrm{~cm}$ and more than $175 \mathrm{~cm}$ or BMI $>40$.

Parturient will be allocated randomly into two equal groups (30 parturient each) using the closed envelops method:

All eligible patients were submitted the following:
Pre-operative screening of all parturients included:

- History taking.

- Complete physical examination.

- Laboratory investigation: CBC, PT, INR, ALT, AST, urea, Cr., FBG, Na \& K.

\section{Anesthetic technique}

Anesthesia technique was standardized in two groups: Group (1):

After complete aseptic technique, spinal injection was performed with the parturient sitting over the operating table with their feet resting on a stool and arms resting on knees at the L3-4 interspace with midline approach by using a 25 gauge needle, after intrathecal injection of $2 \mathrm{ml}(10 \mathrm{mg})$ of $0.5 \%$ hyperbaric bupivacaine and $25 \mu \mathrm{g}$ fentanyl, parturient were placed supine with left uterine displacement with a wedge beneath the right hip to maintain a pelvic tilt. Group (2):

The parturient was placed in the left lateral position with a pillow supporting the head and the operating table horizontal for spinal injection, lumbar puncture was performed after complete aseptic technique in the left lateral position at the L3-4 interspace with midline approach by using a 25 gauge needle, after intrathecal injection of $2 \mathrm{ml}(10 \mathrm{mg})$ of $0.5 \%$ hyperbaric bupivacaine and $25 \mu \mathrm{g}$ fentanyl, parturient were placed supine with left uterine displacement with a wedge beneath the right hip to maintain a pelvic tilt and then repositioned to the supine position with a wedge under the right hip.

\section{The following parameters were measured:}

\section{Hemodynamic measurements:}

1- Heart rate (beat / $\mathrm{min}$ ).

2- Non-invasive measurement of arterial blood pressure (systolic, diastolic \& mean ABP in $\mathrm{mmHg}$ ).

All previous parameters were continously monitored and recorded at the following periods:

- Heart rate and ABP were recorded at 2 min intervals following intrathecal injection till delivery and every 5 min thereafter till the end of surgery.

The incidence of bradycardia, tachycardia and hypotension, atropine and ephedrine requirements were noted.

Hypotension was defined as a decrease in systolic blood pressure greater than $20 \%$ of the baseline.

Ephedrine was given in $6 \mathrm{mg}$ boluses to treat hypotension \& total ephedrine requirements in both groups were recorded \& statistically analysed.

Bradycardia was defined as heart rate less than 60 beats $/ \mathrm{min} .0 .5 \mathrm{mg}$ atropine was given whenever the heart rate becomes less than 50 beats/min. 
II. Sensory blockade characteristics:

Onset of sensory level was assessed bilaterally by loss of sensation to pinprick using a 25 -gauge syringe in the anterior axillary line, assessment was made at 2 min interval until no further rise in block height for $4 \mathrm{~min}$ and for $5 \mathrm{~min}$ thereafter. sensory block to T5 dermatome bilaterally was considered adequate for surgery. Intraoperative discomfort was treated with fentanyl (1 microgram $/ \mathrm{kg}$ ). If the block failed to reach T5 dermatome in $20 \mathrm{~min}$ or if the level reached above $\mathrm{T} 4$, the case was excluded from the study.

\section{Motor block:}

- Motor block was assessed using modified bromage scale. Grade $0=$ full movement; Grade 1= unable to raise extended leg, can bend the knee; Grade $2=$ unable to bend knee, able to flex ankle; Grade 3= no movement

- Assessment was done at 2 min interval till maximum motor block (Grade 3 ) and at half hourly interval thereafter until full movement (Grade 0) will be achieved.

\section{Apgar score:}

The test is done at one minute after birth. Scores 7 and above are generally normal, 4 to 6 fairly low, and 3 and below are generally regarded as critically low.

\section{Patient satisfaction:}

Immediately after applying spinal block, repositioning of patients to the supine position with a wedge under the right hip and prior to the start of surgery, parturient will be asked about their satisfaction for overall comfort level for position ( sitting or lateral ) during spinal anesthesia in terms of three points : not comfortable score 1, comfortable score 2 , very comfortable score 3 .

\section{RESULTS}

I. Haemodynamic measurements:

\section{Changes in the SBP(mmHg)}

There was no significant change in SBP in group (1) and group (2) when measured at admission (baseline), before delivery at $2 \mathrm{~min}, 6 \mathrm{~min}, 8 \mathrm{~min}$ and $10 \min (P=0.67,0.83,0.34,0.55$ and 0.51 respectively) while measurement of SBP at $4 \mathrm{~min}$ showed a significant reduction in group (2) than in group (1) $(\mathrm{P}=0.02)$ and after delivery at $5 \mathrm{~min}, 10$ min, $15 \mathrm{~min} 20 \mathrm{~min}$ and $25 \mathrm{~min}$ there was no significant change in SBP $(\mathrm{P}=0.95,0.13,0.86,0.43$ and 0.06 respectively).

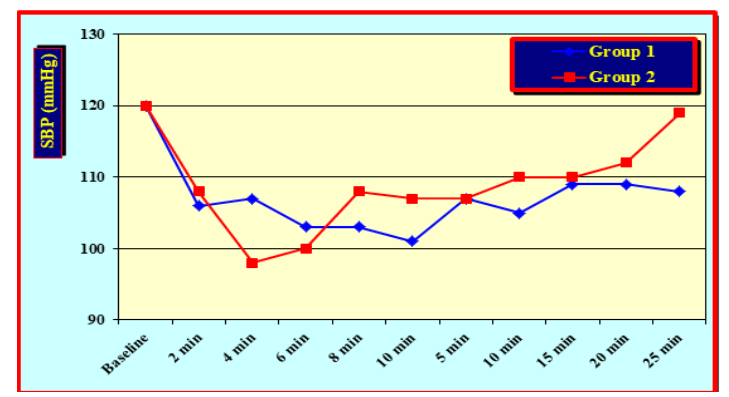

Figure (1): Demonstrates comparison between the two studied groups as regarding SBP.

\section{Changes in the DBP (mmHg)}

There was no significant change in DBP group (1) and group (2) when measured at admission (basline), before delivery at $2 \mathrm{~min}, 6 \mathrm{~min}, 8 \mathrm{~min}$ and $10 \min (\mathrm{P}=0.83,0.33,0.18,0.97$ and 0.72 respectively) while measurement of DBP at $4 \mathrm{~min}$ showed a significant reduction in group (2) than in group (1) $(\mathrm{P}=0.02)$ and after delivery at $5 \mathrm{~min}, 10$ min, $15 \mathrm{~min} 20 \mathrm{~min}$ and $25 \mathrm{~min}$ there was no significant change in DBP $(\mathrm{P}=0.11,0.89,0.57,0.72$ and 0.62 respectively).

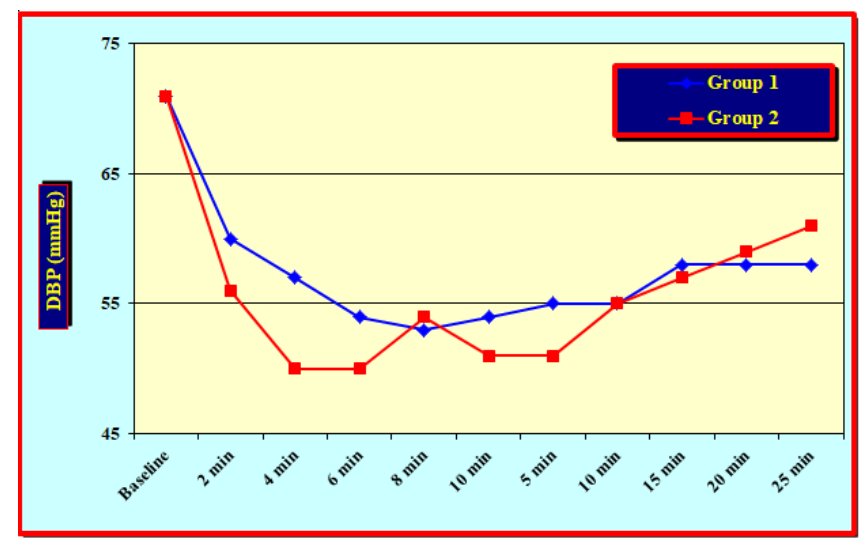

Figure (2): Demonstrates comparison between the two studied groups as regarding DBP.

\section{Changes in the MBP (mmHg).}

There was no significant change in MBP in both group (1) and group (2) when measured at admission (baseline), before delivery at $2 \mathrm{~min}, 6 \mathrm{~min}, 8 \mathrm{~min}$ and $10 \min (\mathrm{P}=0.76,0.58,0.27,0.61$ and 0.78 respectively) while measurement of $\mathrm{MBP}$ at $4 \mathrm{~min}$ showed a significant reduction in group (2) than in group (1) $(\mathrm{P}=0.04)$ and after delivery at $5 \mathrm{~min}, 10$ min, $15 \mathrm{~min} 20 \mathrm{~min}$ and $25 \mathrm{~min}$ there was no significant change $(\mathrm{P}=0.42,0.31,0.91,0.54$ and 0.32 respectively). 


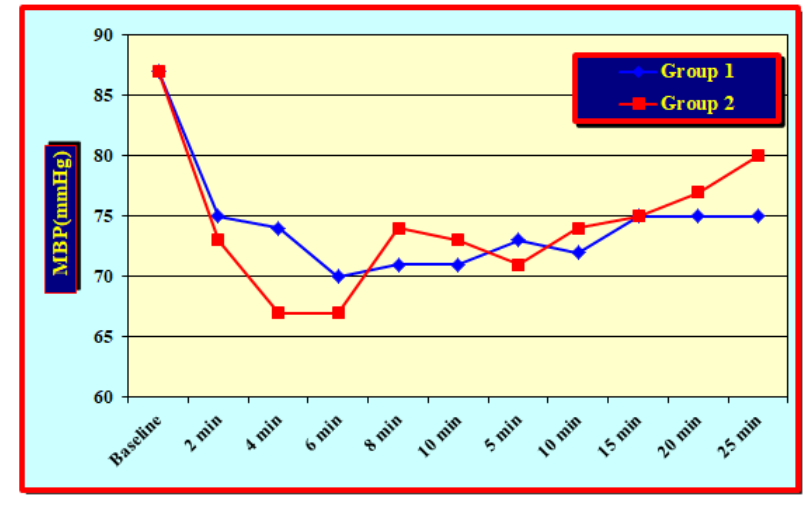

Figure (3): Demonstrates comparison between the two studied groups as regarding MBP.

\section{The incidence of hypotension}

Hypotension was detected in $9 / 30$ cases of group (1) (30\%) and the remaining of group (1) 21/30 we didn't detect hypotension (70\%); while in group (2) we detect hypotension in $12 / 30$ cases $(40 \%)$ and the remaining $18 / 30$ cases $(60 \%)$ didn't show hypotension.

The statistical analysis revealed that inspite of hypotension was common in group (2) but there was no significant difference regarding the incidence of occurrence of hypotension $(\mathrm{p}=0.23)$.

Table (1): Demonstrates comparison between the two studied groups as regarding hypotension

\begin{tabular}{|l|l|l|l|l|l|}
\hline \multirow{2}{*}{ Hypotension } & \multicolumn{2}{|c|}{ Group 1 } & \multicolumn{2}{|c|}{ Group 2 } & \multirow{2}{*}{ P } \\
\cline { 2 - 5 } & No & $\%$ & No & $\%$ & \\
\hline Detected & 9 & $30 \%$ & 12 & $40 \%$ & \multirow{2}{*}{0.23} \\
Notdetected & 21 & $70 \%$ & 18 & $60 \%$ & \\
\hline
\end{tabular}

$\mathrm{P}$ significant when $\leq 0.05$

\section{Ephedrine requirements}

In group (1) ephedrine requirement ranged between 6-24 $\mathrm{mg}$ with a mean dose of $12.64 \pm 5.96 \mathrm{mg}$ while in group (2) ephedrine requirements ranged between $6-36 \mathrm{mg}$ with a mean dose of $13 \pm 7.73 \mathrm{mg}$ and the statistical analysis revealed that there was no significant statistical difference between both groups regarding the need for ephedrine $(\mathrm{p}=0.84)$.

Table (2):Demonstrates comparison between the two studied groups as regarding ephedrine requirement

\begin{tabular}{|c|c|c|c|}
\hline Ephedrine (mg) & Group 1 & Group 2 & P \\
\hline Mean \pm S.D & $12.64 \pm 5.96$ & $13 \pm 7.73$ & 0.84 \\
\hline
\end{tabular}

$P$ significant when $\leq 0.05$

\section{Changes in the HR (beat/min)}

There was no significant change in heart rate in both group (1) and group (2) when measured at admission (baseline), before delivery at $4 \mathrm{~min}, 6 \mathrm{~min}, 8 \mathrm{~min}$ and $10 \mathrm{~min}(\mathrm{P}=0.19,0.10,0.12,0.44$ and 0.77 respectively) while measurement of mean heart rate 2 min showed a significant increase in heart rate of patients of group (2) than in those of group (1) $(\mathrm{P}=0.010)$ and after delivery at $5 \mathrm{~min}, 10 \mathrm{~min}, 15 \mathrm{~min} 20 \mathrm{~min}$ and $25 \mathrm{~min}$ there was no significant change in heart rate $(\mathrm{P}=0.13,0.26,0.32,0.10$ and 0.33 respectively).

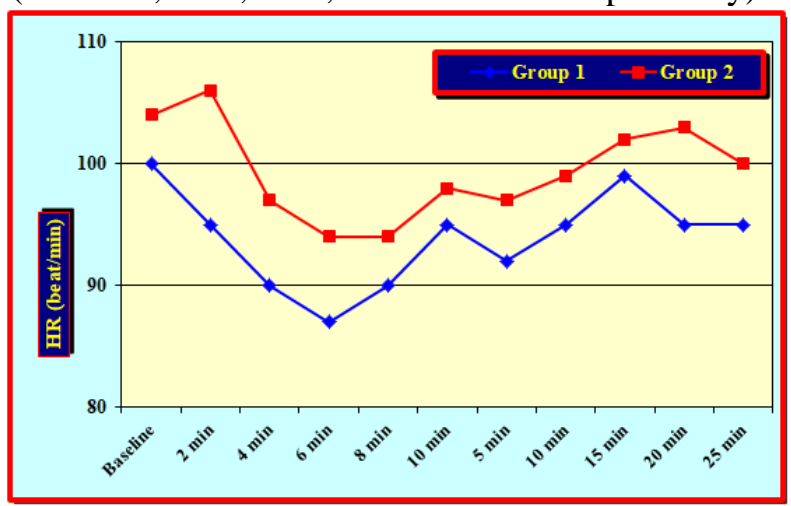

Figure (4): Demonstrates comparison between the two studied groups as regarding heart rate 
The incidence of bradycardia

Bradycardia was detected in 6/30 cases of group (1) (20\%), while in group (2) we detect bradycardia in 5/30 cases (16.7\%). $3 / 6$ cases of group (1) and $2 / 5$ of group (2) were corrected by atropine as HR was $<50$.

The statistical analysis revealed that there was no significant statistical difference between both groups neither regarding the incidence of bradycardia $(\mathrm{p}=0.23)$.

Table (3): Demonstrates comparison between the two studied groups as regarding the incidence of bradycardia

\begin{tabular}{|c|c|c|c|c|c|}
\hline \multirow{2}{*}{ Bradycardia } & \multicolumn{2}{|c|}{ Group 1} & \multicolumn{2}{|c|}{ Group 2} & \multirow{2}{*}{$\mathbf{P}$} \\
\hline & No & $\%$ & No & $\%$ & \\
\hline $\begin{array}{l}\mathrm{HR}<60(\text { beat } / \mathrm{min}) \\
\mathrm{HR}>60(\mathrm{beat} / \mathrm{min})\end{array}$ & $\begin{array}{c}6 \\
24\end{array}$ & $20 \%$ & $\begin{array}{c}5 \\
25\end{array}$ & $\begin{array}{l}16.7 \% \\
33.3 \%\end{array}$ & 0.36 \\
\hline
\end{tabular}

\section{Sensory blockade characteristics}

\section{Comparison for sensory level (Thoracic) between both groups}

regarding the level of sensory block there was a significant difference in the onset of sensory blockade level between both groups ( 1 and 2$)$ till the 10th $\min (P=0.002,0.003,0.001$ and 0.040 respectively) except at 2 min $(p$ $=0.197$ ) while there was no statistical significant difference between both groups regarding level of sensory block from 12 th $\mathrm{min}$ till the end of the procedure at $12 \mathrm{~min}, 14 \mathrm{~min}, 16 \mathrm{~min} 18 \mathrm{~min}$ and the end $(\mathrm{P}=0.073,0.795,0.795$, 0.795 and 1 respectively).

Table (4): Demonstrates comparison between the two studied groups as regarding sensory block

\begin{tabular}{|c|l|l|c|}
\hline \multirow{2}{*}{$\begin{array}{l}\text { Level sensory } \\
\text { block }\end{array}$} & \multicolumn{2}{|c|}{ Level of sensory block (Thoracic) } & \multirow{2}{*}{ P } \\
\cline { 2 - 4 } & Group 1 (Mean \pm S.D) & Group 2 (Mean \pm S.D) & \\
\hline 2 min & $11 \pm 1$ & $11 \pm 1$ & 0.197 \\
4 min & $9 \pm 1$ & $8 \pm 1$ & $0.002 *$ \\
8 min & $8 \pm 1$ & $6 \pm 1$ & $0.003 *$ \\
10 min & $6 \pm 1$ & $5 \pm 1$ & $0.001 *$ \\
12 min & $5 \pm 1$ & $4 \pm 1$ & $0.040^{*}$ \\
14 min & $5 \pm 1$ & $4 \pm 1$ & 0.073 \\
16 min & $4 \pm 1$ & $4 \pm 1$ & 0.795 \\
18 min & $4 \pm 1$ & $4 \pm 1$ & 0.795 \\
At the end & $4 \pm 1$ & $5 \pm 0$ & $\mathbf{1 . 7 9 5}$ \\
\hline
\end{tabular}

*: Statistically significant at $\mathrm{p} \leq 0.05$

The onset time of satisfactorysensory level (T5)

Patients of group (2) reached T5 sensory block faster than patients of group (1) at 6th, 8th, 10th and 12th min respectively $(p=0.012,0.231,0.021$ and 0.035 respectively).

Table (5): Demonstrates comparison between the two studied groups as regarding time to reach $\mathrm{T5}$

\begin{tabular}{|c|c|c|c|c|c|}
\hline \multirow{2}{*}{ Time to reach $T_{5}$} & \multicolumn{2}{|c|}{ Group 1} & \multicolumn{2}{|c|}{ Group 2} & \multirow{2}{*}{$\mathbf{P}$} \\
\hline & $\overline{\text { No }}$ & $\%$ & $\overline{\mathrm{No}}$ & $\%$ & \\
\hline $\begin{array}{l}6 \mathrm{~min} \\
8 \mathrm{~min} \\
10 \mathrm{~min} \\
12 \mathrm{~min}\end{array}$ & $\begin{array}{l}2 \\
9 \\
13 \\
6\end{array}$ & $\begin{array}{l}6.7 \% \\
30 \% \\
43.3 \% \\
20 \%\end{array}$ & $\begin{array}{l}13 \\
11 \\
5 \\
1\end{array}$ & $\begin{array}{l}43.3 \% \\
36.7 \% \\
16.7 \% \\
3.3 \%\end{array}$ & $\begin{array}{l}0.012 * \\
0.231 \\
0.021 * \\
0.035 *\end{array}$ \\
\hline
\end{tabular}

$P$ significant when $\leq 0.05$ 


\section{Comparison for maximal sensory level between both groups}

The maximal sensory block in group (1) reaches T4 in 18/30 cases (60\%) and T5 in 12/30cases (40\%) while in group (2) the maximal sensory block reached T4 in $19 / 30$ cases $(63.3 \%)$ and T5 in 11/30 cases (36.7\%) and the statistical analysis revealed that there was no significant statistical difference between both groups regarding the maximal level of sensory block ( $\mathrm{p}=0.23$ and 0.35 respectively)

Table (6): Demonstrates comparison between the two studied groups as regarding maximal sensory level

\begin{tabular}{|c|l|l|l|l|l|}
\hline \multirow{2}{*}{ Dermatome } & \multicolumn{2}{|c|}{ Group (1) } & \multicolumn{2}{|c|}{ Group (2) } & \multirow{2}{*}{ P } \\
\cline { 2 - 5 } & No & $\%$ & No & $\%$ & \\
\hline T4 & 18 & $60 \%$ & 19 & $53.3 \%$ & 0.23 \\
T5 & 12 & $40 \%$ & 11 & $\mathbf{3 6 . 7 \%}$ & 0.35 \\
\hline
\end{tabular}

P significant when $\leq 0.05$

\section{Assessment of motor block}

showed that there was no significant statistical difference between both groups regarding the grade of motor block when assessed at $2 \mathrm{~min}, 4 \mathrm{~min}, 6 \mathrm{~min}, 8 \mathrm{~min}, 10 \mathrm{~min}, 30 \mathrm{~min}, 60 \mathrm{~min}, 90 \mathrm{~min}, 120 \mathrm{~min}$, and $150 \mathrm{~min}(\mathrm{P}=$ $0.22,0.23,0.31,0.22,0.22,0.23,0.23,0.22,0.32$ and 0.22 respectively

Table (7): Comparison between the two studied groups as regarding motor block

\begin{tabular}{|c|c|c|c|c|c|c|c|c|c|}
\hline \multirow{3}{*}{$\begin{array}{l}\text { Motor } \\
\text { grading }\end{array}$} & \multicolumn{8}{|c|}{ Grading of motor block ( $\mathrm{T}$ level) } & \multirow{3}{*}{$\mathbf{P}$} \\
\hline & \multicolumn{2}{|c|}{ G0 } & \multicolumn{2}{|c|}{ G1 } & \multicolumn{2}{|c|}{ G2 } & \multicolumn{2}{|c|}{ G3 } & \\
\hline & G (1) & G (2) & G (1) & G (2) & G (1) & G (2) & G (1) & G (2) & \\
\hline $2 \min$ & 0 & 0 & 20 & 20 & 10 & 10 & 0 & 0 & 0.22 \\
\hline $4 \mathrm{~min}$ & 0 & 0 & 0 & 0 & 20 & 20 & 10 & 10 & 0.23 \\
\hline 6 min & 0 & 0 & 0 & 0 & 4 & 1 & 26 & 29 & 0.31 \\
\hline $8 \min$ & 0 & 0 & 0 & 0 & 0 & 0 & 30 & 30 & 0.22 \\
\hline At the end & 0 & 0 & 0 & 0 & 0 & 0 & 30 & 30 & 0.22 \\
\hline $30 \min$ & 0 & 0 & 0 & 0 & 19 & 22 & 11 & 8 & 0.23 \\
\hline $60 \mathrm{~min}$ & 0 & 0 & 0 & 1 & 30 & 29 & 0 & 0 & 0.23 \\
\hline $90 \mathrm{~min}$ & 0 & 0 & 13 & 20 & 17 & 10 & 0 & 0 & 0.22 \\
\hline $120 \mathrm{~min}$ & 8 & 18 & 22 & 18 & 0 & 0 & 0 & 0 & 0.32 \\
\hline $150 \mathrm{~min}$ & 22 & 12 & 0 & 0 & 0 & 0 & 0 & 0 & 0.22 \\
\hline
\end{tabular}

*: Statistically significant at $\mathrm{p} \leq 0.05$

\section{Assessment of Apgar score}

All babies of group (1) and group (2) had APGAR score of 10 and the statistical analysis revealed that there was no significant difference between babies of both groups regarding APGAR score $(\mathrm{P}=1)$.

\section{Assessment of patient satisfaction}

In group (1) $20 / 30$ cases were comfortable about the technique (66.7\%), 5/30 cases were very comfortable during the technique $(16.7 \%)$ and another $5 / 30$ cases were not comfortable by the technique $(16.7 \%)$ while in group (2) $14 / 30$ cases (46.7\%) were comfortable, $3 / 30$ cases (10\%) were very comfortable and $13 / 30$ cases (43.3\%) were not comfortable during the technique.

The statistical analysis revealed that satisfied cases (comfortable, very comfortable) were statistically significant in setting position than in lateral position $(\mathrm{p}=0.021$ and 0.035 respectively) while disappointment was significant in cases of group of lateral position $(\mathrm{p}=0.01)$. 


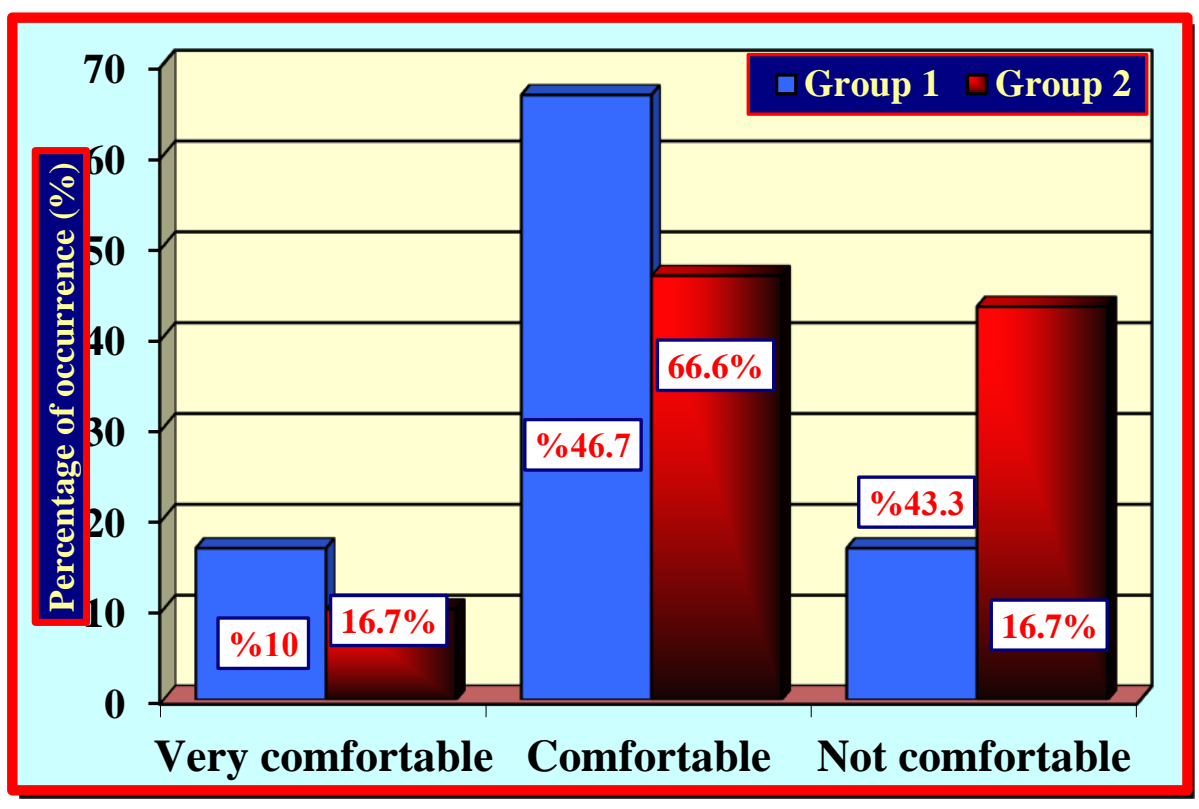

Figure (5): Demonstrates comparison between the two studied groups as regarding patient satisfaction

\section{DISCUSSION}

In the study, we compared the effect of two different positions (sitting versus left lateral) during the induction of spinal anesthesia in cesarean section on the hemodynamics and the block characteristics., this study was carried on 60 cases which were subdivided into 2 groups, 30 parturient each, Hyperbaric bupivacaine $0.5 \% \quad(2 \mathrm{ml})$ and 25 microgram of fentanyl were injected intrathecally, 30 parturient in the sitting position (group 1) and 30 parturient in the lateral position (group 2) then the patient was returned immediately to the supine wedged position .

In the study there was no statistically significant difference in demographic data regarding the patient's age, weight and height.

Hypotension was defined as a decrease in systolic blood pressure greater than $20 \%$ of the baseline, Although in the present study hypotension occurred in the lateral group (40\%) more than in the sitting group (30\%), this difference was not significant $(\mathrm{p}=0.231)$.

In accordance with the study, Ortiz-Gomezet al. ${ }^{(10)}$, Chevuri et al..$^{(11)}$ and Prakash et al. ${ }^{(12)}$ studied the effect of position on maternal hemodynamics during elective caesarean delivery under spinal anesthesia, they found that there was no significant difference in arterial hypotension between the studied groups.

Inglis $\boldsymbol{e t}$ al. ${ }^{(13)}$ studied the effect of maternal position (right lateral versus sitting position) during induction of spinal anesthesia for Caesarean section on forty pregnant females. They found that although hypotension was more common in the lateral group, this was not significant.
In contrast with the present study, Coppejans et al. ${ }^{(14)}$ compared sitting versus lateral position during initiation of small-dose combined spinal epidural anesthesia (CSE), they found that there was significant increase in the incidence of hypotension in the lateral group more than with the sitting group.

Ephedrine was given in $6 \mathrm{mg}$ boluses to treat hypotension, the present study showed that the total ephedrine requirement in the lateral group $(13 \pm 7.73$ $\mathrm{mg}$ ) was higher than that in the sitting group $(12.64 \pm 5.96 \mathrm{mg})$, but this was statistically not significant, $(\mathrm{p}=0.844)$.

In accordance with the study, Ortiz-Gomezet $\boldsymbol{a l}^{\left({ }^{(10)}\right)}$ and Prakash et $\boldsymbol{a l l}^{\left({ }^{(12)}\right.}$ found that there was no significant difference between both groups regarding the total ephedrine requirement.

Inglis et $\boldsymbol{a l}^{(\mathbf{1 3 )}}$ found that there was an increased requirement for ephedrine in the first 10min after spinal injection in the lateral group, in keeping with the faster onset of block at this time, although overall ephedrine requirements were comparable, which is in accordance with the results regarding the total ephedrine requirement .

Bradycardia was defined as heart rate less than 60 beats $/ \mathrm{min}$. In the study the incidence of bradycardia was higher in the sitting group (20\%) than in the lateral group $(16.7 \%)$, but this difference was statistically not significant $(\mathrm{p}=0.231)$.

In accordance with the present study, Ortiz et al. ${ }^{(10)}$, Chevuri et al. ${ }^{(11)}$, Prakash et al. ${ }^{(12)}$ and Inglis

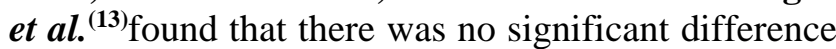
between the studied groups regarding the heart rate.

The onset of sensory block was significantly faster in the lateral group than in the sitting group, Patients of lateral group reached T5 sensory block 
faster than patients of the sitting group at 6th, 8 th, 10 th and 12th $\min (\mathrm{p}=0.012,0.231,0.021$ and 0.035 respectively) \& that there was no significant statistical difference between both groups regarding the maximal level of sensory block $(\mathrm{T} 4, \mathrm{~T} 5)(\mathrm{p}=0.231$ and 0.354 respectively). However, the motor block was the same in both groups regarding the degree of block .

In accordance with the study, Chevuri et al. ${ }^{(11)}$ and Inglis et al. ${ }^{(13)}$ found that there was a faster onset of sensory block to a higher level in lateral group but there was no significant difference between both groups regarding the maximal sensory level or in the degree of motor block .

In contrast with the present study, Prakash $\boldsymbol{e t}$ $\boldsymbol{a l} .^{(12)}$ found that there was no significant difference in the onset of sensory block, but they found that there was no significant difference between both groups regarding the motor block which is in accordance with the present study.

The statistical analysis revealed that there was no significant difference between babies of both groups regarding APGAR score $(\mathrm{P}=1)$.

In accordance with the present study, Atashkhoei $\boldsymbol{e t} \boldsymbol{a l} .{ }^{(15)}$ found that there was no significant difference between both groups regarding APGAR score .

In the present study, sitting position was more comfortable for the parturient than the lateral position as satisfied cases (comfortable, very comfortable) were statistically significant in setting position than in lateral position $(\mathrm{p}=0.021$ and 0.035 respectively) during spinal anesthesia for cesarean section.

In accordance with the present study, OrtizGomezet al. ${ }^{(\mathbf{1 0})}$ found that the sitting position is easier for performing spinal anesthesia and more comfortable for the parturient.

From the present results and discussion, both Left lateral and sitting position in spinal anesthesia in cesarean section have the same effect on hemodynamics, also satisfactory sensory and motor block can be achieved in both positions. So left lateral position is safe and can be performed in parturient who are sedated, in pain or using entonox. Also in certain obstetric complication, such as prolapsed cord which may preclude the sitting position it is better to perform spinal anesthesia in the left lateral position.

\section{CONCLUSION}

Satisfactory sensory and motor blockade were successfully achieved in both sitting and lateral positions during intrathecal injection in cesarean section without significant difference in the hemodynamic changes or motor blockade. With superiority of faster onset of sensory blockade in lateral position, while sitting position is more comfortable for he parturient.

\section{REFERENCES}

1. Althabe F, and Belizan JF (2006): Caesarean section: The paradox. The Lancet, 368:1472-3.

2. Savage W (2007): The rising caesarean section rate: a loss of obstetric skill. J Obstet Gynaecol., 27(4):339-46.

3. Ching T, Kanagalingam D, Hak Koon T (2003): Rising Caesarean Section Rates-Where Do We Go From Here? SGH Proceedings, 12:208-12

4. Raja J, Mikhail M (2006): Obstetric anesthesia. In: Morgan GE, Mikhail M, Murray M (eds). Clinical anesthesiology. $4^{\text {th }}$ ed. New York: McGraw-Hill Medical, pp890- 921.

5. Bucklin BA, Hawkins JL, Anderson JR et al. (2005): Obstetric anesthesia workforce survey: twenty year update. Anesthesiology, 103:645-53.

6. Banks A, Levy D (2007): General anaesthesia for operative obstetrics. Anaesth Intens Care Med., 8:317-9.

7. Cyna AM, Andrew M, Emmett RS et al. (2006): Techniques for preventing hypotension during spinal anaesthesia for caesarean section. Cochrane Database Syst Rev., 4: 235-239.

8. Saracoglu KT, Saracoglu A, Umuroglu T et al. (2012): Neuraxial block versus general anaesthesia for cesarean section: post-operative pain scores and analgesic requirements. J Pak Med Assoc., 62(5):441-4

9. Glosten B (2000): Anaesthesia for obstetrics. In: Miller ED Jr, Cucchiara RF, Reves JG, Roizen MF, Savares JJ (eds). Anaesthesia. $5^{\text {th }}$ ed. Vol.2. London: Churchill Livingstone; pp.2024- 68.

10. Ortiz-Gomez JR, Palacio-Abizanda FJ, MorillasRamirez F et al. (2015): Effect of position on maternal haemodynamics during elective caesarean delivery under spinal anaesthesia. Anestezjologia I Ratownictwo., 9: 22-9.

11. Chevuri SB, Rao JS, Chandergutti $V$ et al. (2015): A Comparative Study of Effects of Sitting and Lateral Positions on Quality of Block during Induction of Spinal Anaesthesia in Patients Undergoing Cesarean Section. J Cont Med A Dent., 3(1):93-94.

12. Prakash S, Chaudhary K, Gogia AR et al. (2013): A prospective, randomized controlled trial comparing the left lateral, modified lateral and sitting positions for spinal block characteristics for Cesarean delivery. Minerva Anestesiol., 79(6):652-60.

13. Inglis A, Daniel M and McGrady E (1995):Maternal position during induction of spinal anaesthesia for caesarean section. A comparison of right lateral and sitting positions. Anesthesia, 50(4):363-5.

14. Coppejans HC, Hendrickx E, Goossens J et al. (2006): The sitting vs lateral position during combined spinal epidural anesthesia for CS: Block characteristics and severity of hypotension. Anesthesia Analgesia, 102(1):2437.

15. Atashkhoei S, Abri R, Naghipour B et al. (2018):Effect of Glucose Containing Crystalloid Infusion on Maternal Hemodynamic Status After Spinal Anesthesia for Cesarean Section. Anesth Pain Med., 8(4):801-804. 